\title{
Supplementary for:
}

Photocatalytic Rejuvenation Enabled Self-Sanitizing, Reusable, and Biodegradable Masks against COVID-19

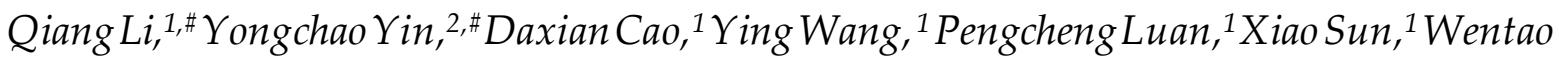 \\ Liang, ${ }^{3}$ Hongli Zhu ${ }^{1, *}$
}

${ }^{1}$ Department of Mechanical and Industrial Engineering, Northeastern University, Boston, MA

02115, USA

${ }^{2}$ Department of Biology, Northeastern University, Boston, MA 02115, USA

${ }^{3}$ Kostas Advanced Nanocharacterization Facility (KANCF), Northeastern University, Burlington,

MA 01803, USA

\#These authors contributed equally.

Boston, MA 02115, USA

*Corresponding author: Dr. Hongli Zhu; E-mail: $\underline{\text { h.zhu@ @eu.edu }}$ 


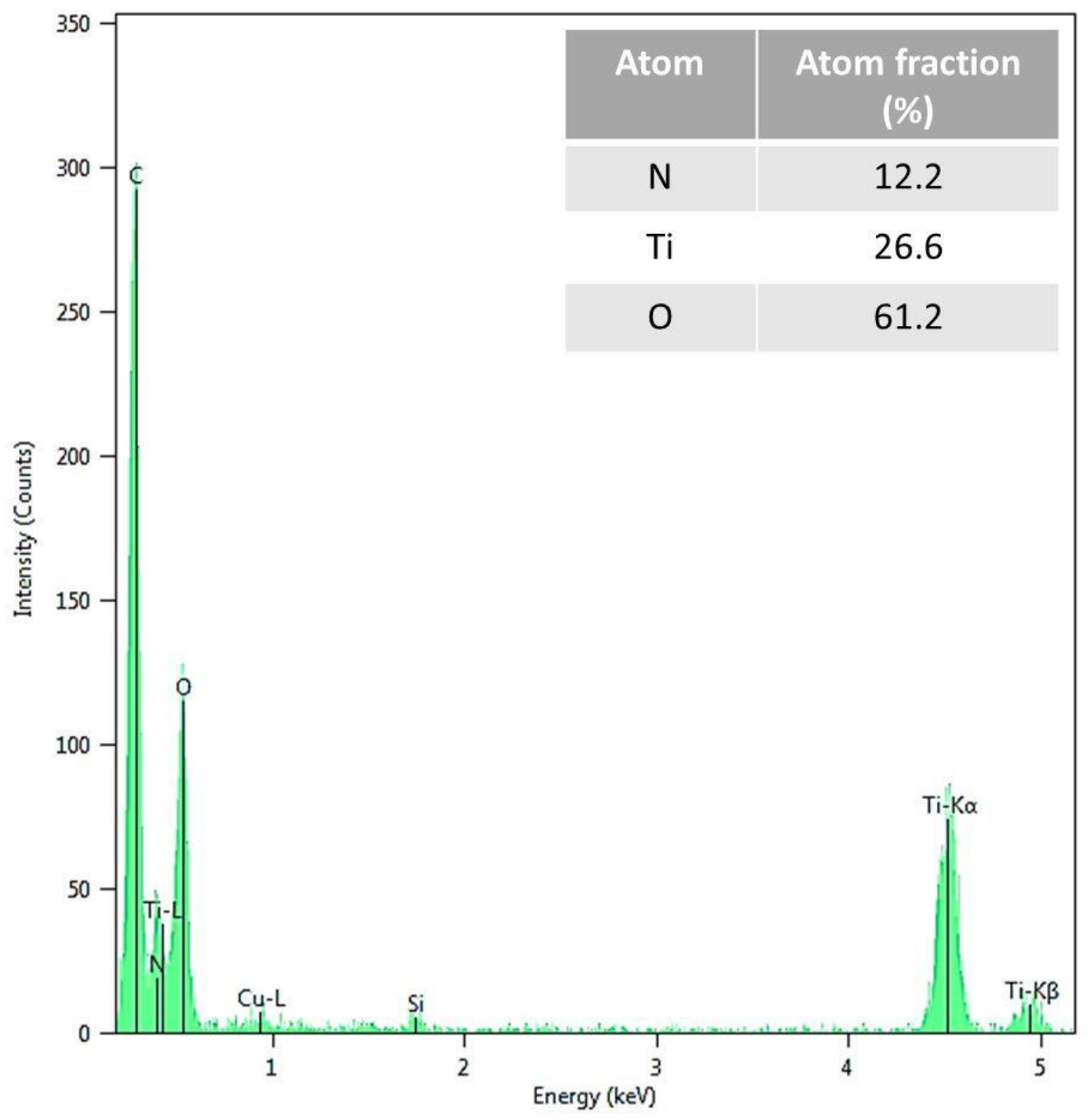

Figure S1. Energy dispersive X-ray spectroscopy (EDX) and the atom fraction (\%) of N, Ti, and $\mathrm{O}$ in the $\mathrm{N}-\mathrm{TiO}_{2}$. The percentage of each atom in $\mathrm{N}-\mathrm{TiO}_{2}$ was calculated based on the total atom fraction of $\mathrm{N}, \mathrm{Ti}$, and $\mathrm{O}$. 
Table S1. The composition of the mimicking sunlight used in this study by total energy.

\begin{tabular}{lccc}
\hline Light & Output power (W) & Percentage $(\%)$ & Spectral output (nm) \\
\hline Total radiance & 50 & 100 & $200-2500$ \\
UV light & 2.6 & 5.2 & $<390$ \\
Visible light & 18.6 & 37.2 & $390-770$ \\
Infrared light & 28.8 & 57.6 & $>770$ \\
\hline
\end{tabular}




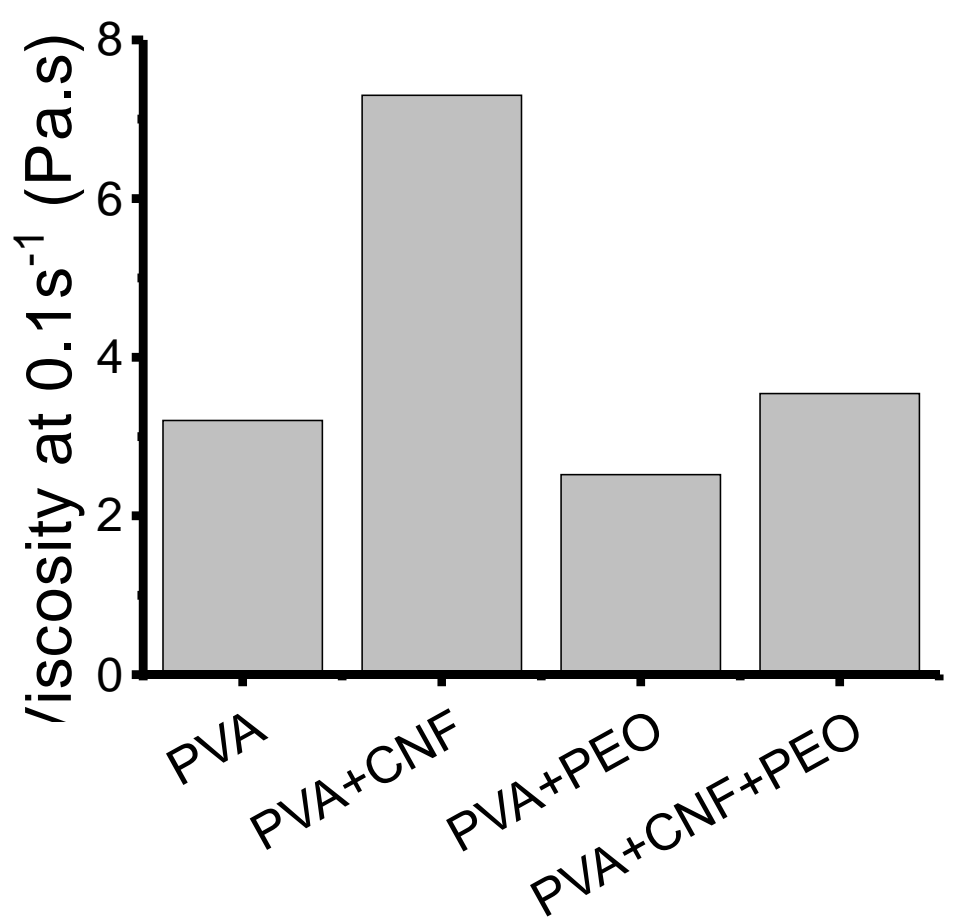

Figure S2. The viscosity of electrospinning dopes at the shear rate of $0.1 \mathrm{~S}^{-1}$. The inserted blue dash line indicates the viscosity of the PVA. 

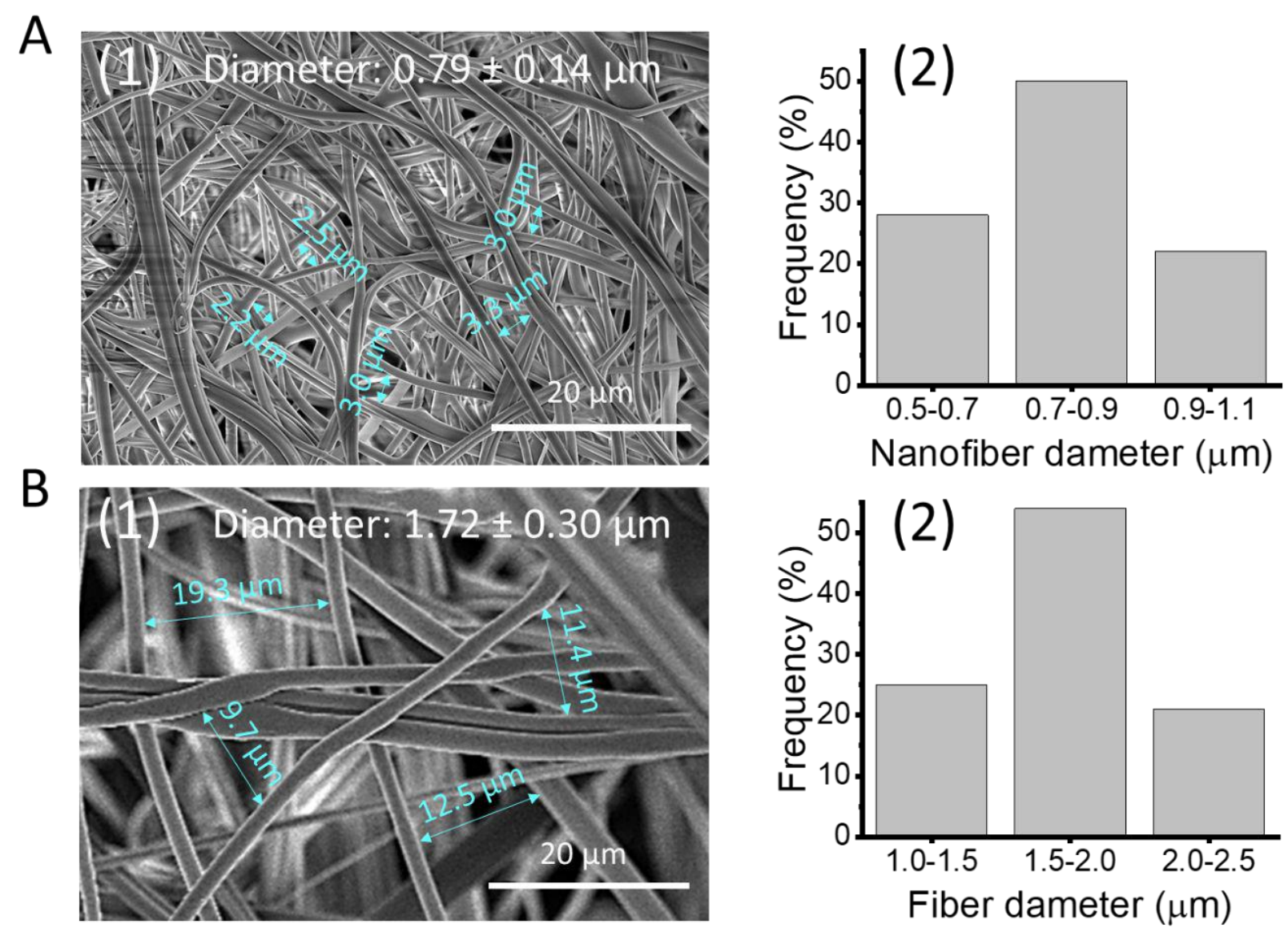

Figure S3. A. as-electrospun mask of PVA+CNF+PEO; B. a commercial surgical mask. The SEM images in the panel-1 display the morphologies, diameters, and porous structure and their size (inserted light blue arrows and numbers) of the mask materials. The histograms in the panel-2 decipher the frequency of the diameter distributions. 

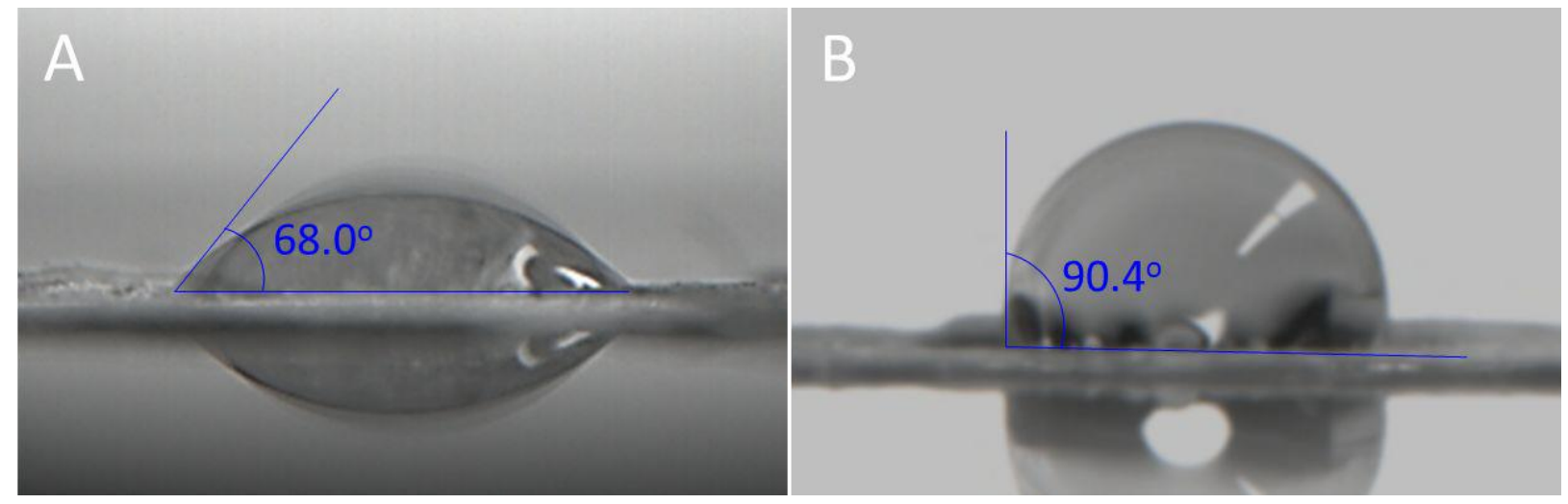

Figure S4. Contact angle of the mask. A. N-TiO 2 deposition first and then esterification with stearic acid. B. deposition of $\mathrm{N}-\mathrm{TiO}_{2} / \mathrm{TiO}_{2}$ mixture at a weight ratio of 1:1. 


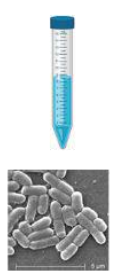

E. coli

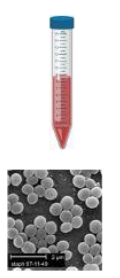

S. aureus

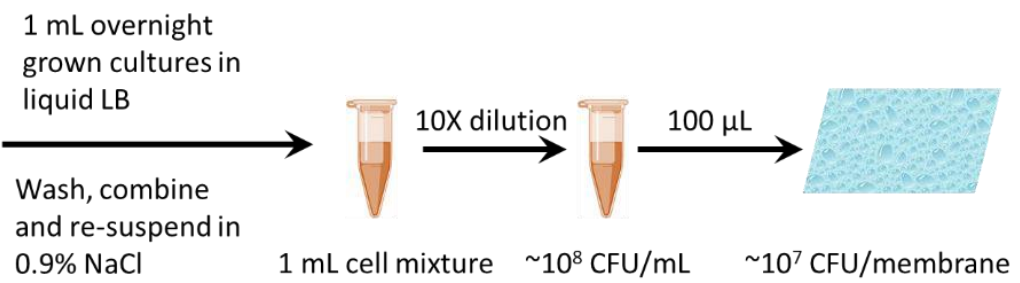

$0.9 \% \mathrm{NaCl}$

$1 \mathrm{~mL}$ cell mixture $\quad \sim 10^{8} \mathrm{CFU} / \mathrm{mL} \quad \sim 10^{7} \mathrm{CFU} /$ membrane

Photocatalytic treatments Wash/resuspend

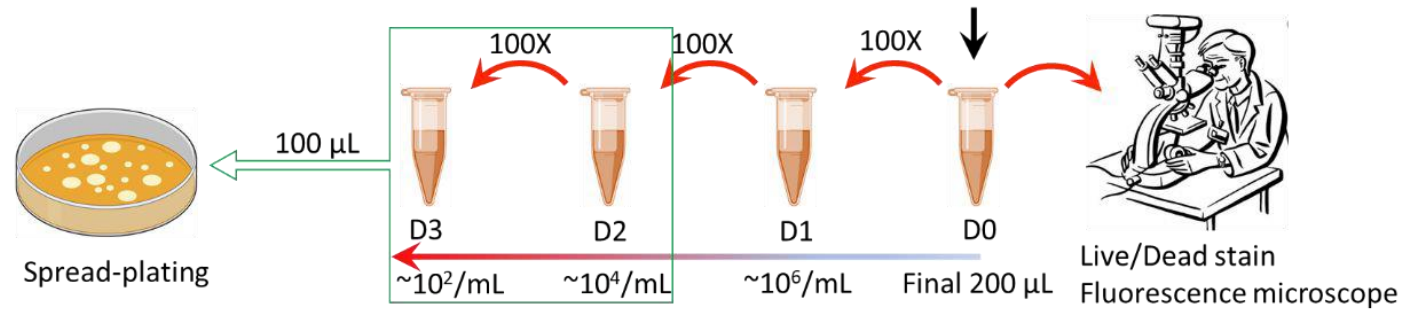

The colonies represent total CFU/ $100 \mu \mathrm{L}$. The dilution factor in $\mathbf{D} 3$ is $10^{7}(100 \times 100 \times 100 \times 10)$

To calculate initial CFU in cell suspension: Colonies on D3 plate $\times 10^{7} / \mathrm{mL}$

To calculate initial CFU on membranes: Colonies on D3 plate $\times 10^{6} / \mathrm{mL}$

Figure S5. Schematic of antibacterial and photocatalytic rejuvenation test. 

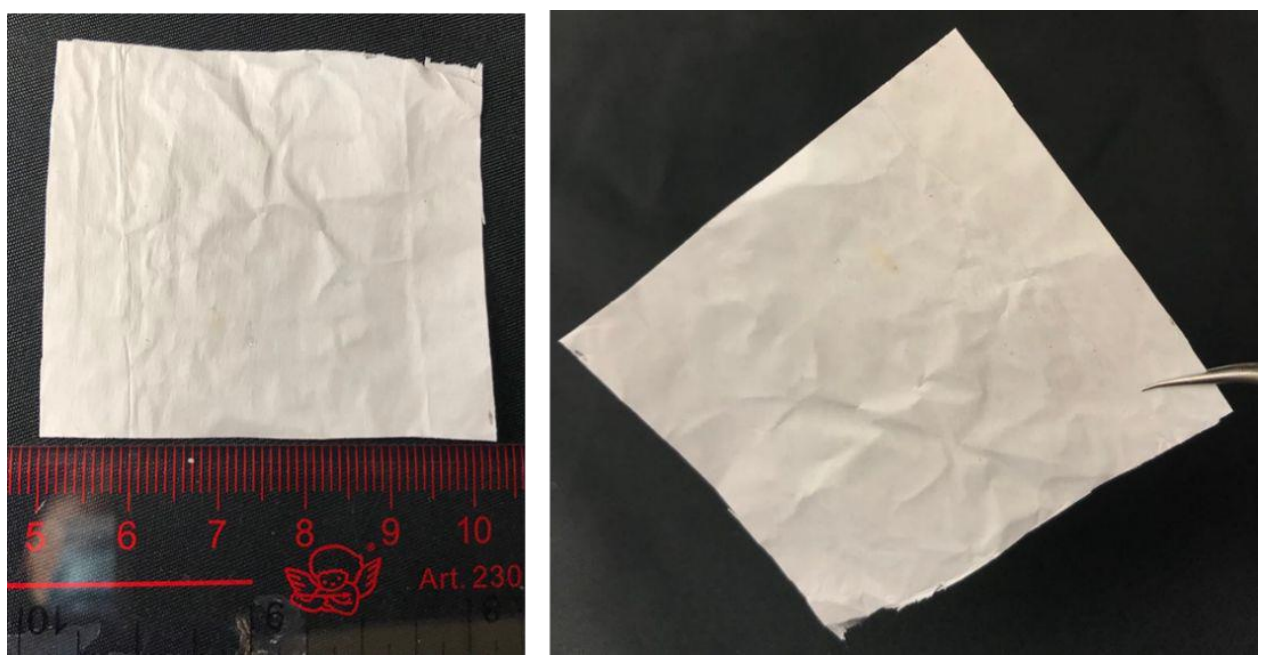

Figure S6. Photo images of as-electrospun mask that has been cut into a size of $5 \mathrm{~cm}$ by $5 \mathrm{~cm}$ for mounting bacteria. 

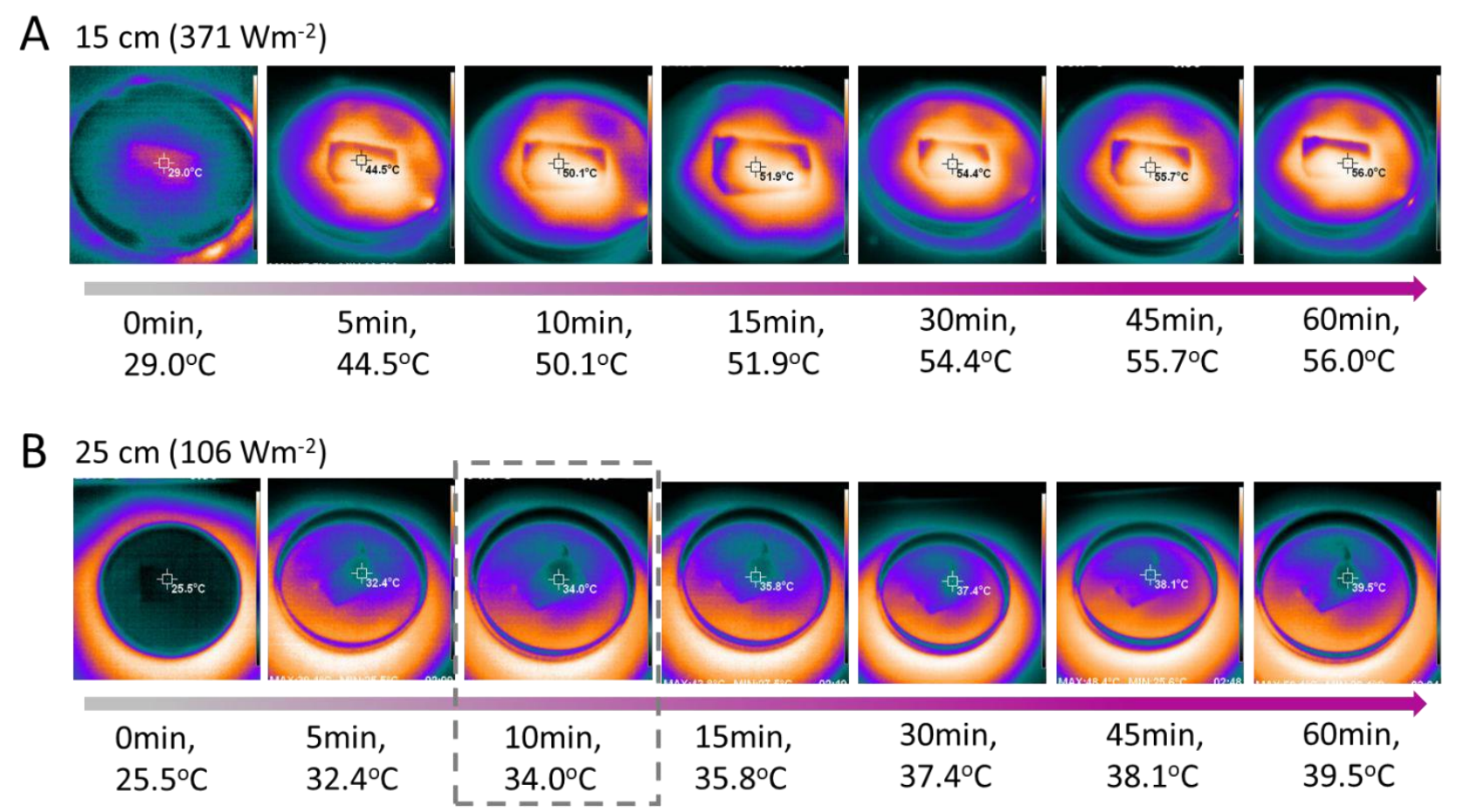

Figure S7. Thermal images of temperature distributions by using an IR camera for bacteriamounted mask materials. The mask material was put in a petri dish and placed under the light of a solar simulator. The distance between the sample and the light was kept for $15 \mathrm{~cm}$ (A) and $25 \mathrm{~cm}$ (B), where the illumination was at about 0.37 Sun $\left(371 \mathrm{Wm}^{-2}\right)$ and 0.1 Sun $\left(106 \mathrm{Wm}^{-2}\right)$, respectively. The temperature was detected by using a thermal image camera for illumination after $0,5,10,15,30,45$, and $60 \mathrm{~min}$. The condition selected in our research for sunlight irradiation was highlighted by a dashed rectangle. 

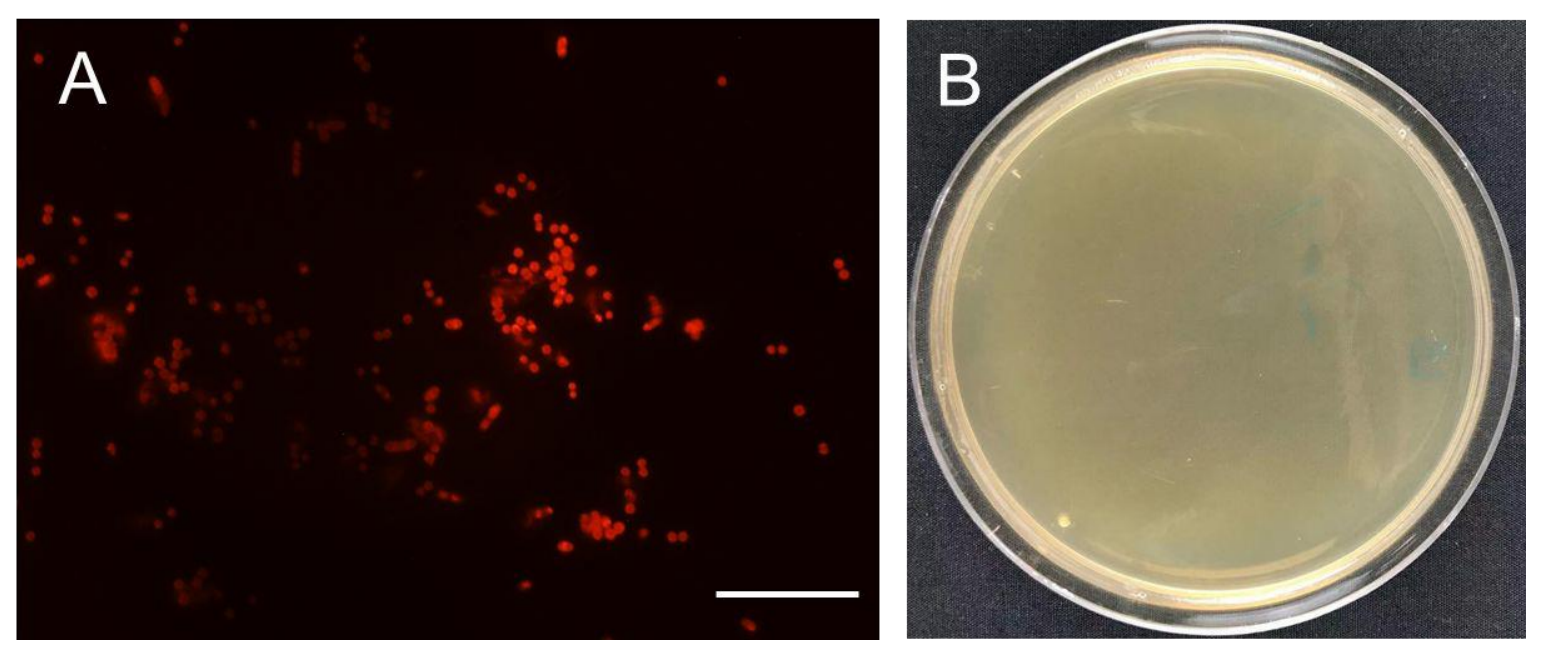

Figure S8. Photocatalytic rejuvenation of mask deposited with $\mathrm{N}-\mathrm{TiO}_{2} / \mathrm{TiO}_{2}$ mixture at a weight ratio of 1:1. A. fluorescence microscopic image of bacteria mounted on mask; red indicates dead bacteria and green indicates alive bacteria; bar is $20 \mu \mathrm{m}$. B. photo images of plate incubation. Both images were taken after light irradiation. 


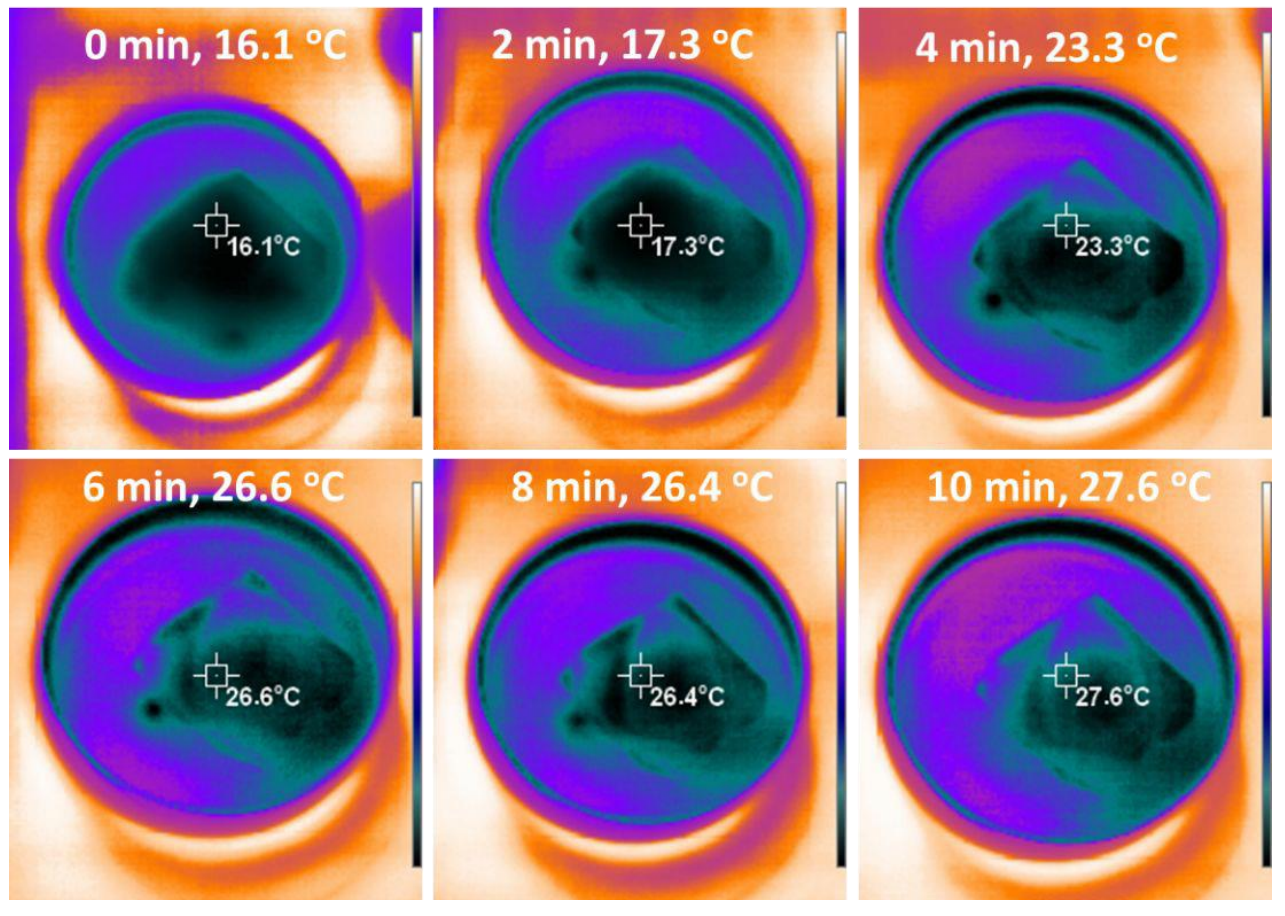

Figure S9. The change of temperature when our mask was irradiated under real sunlight for 10 min. The thermal images were taken by using an IR camera (HT-18, HTI, Dongguan, China), and the light density was measured at about $0.67 \mathrm{Sun}\left(664 \mathrm{Wm}^{-2}\right)$ by using a solar power meter (also see Figure 4F1). 

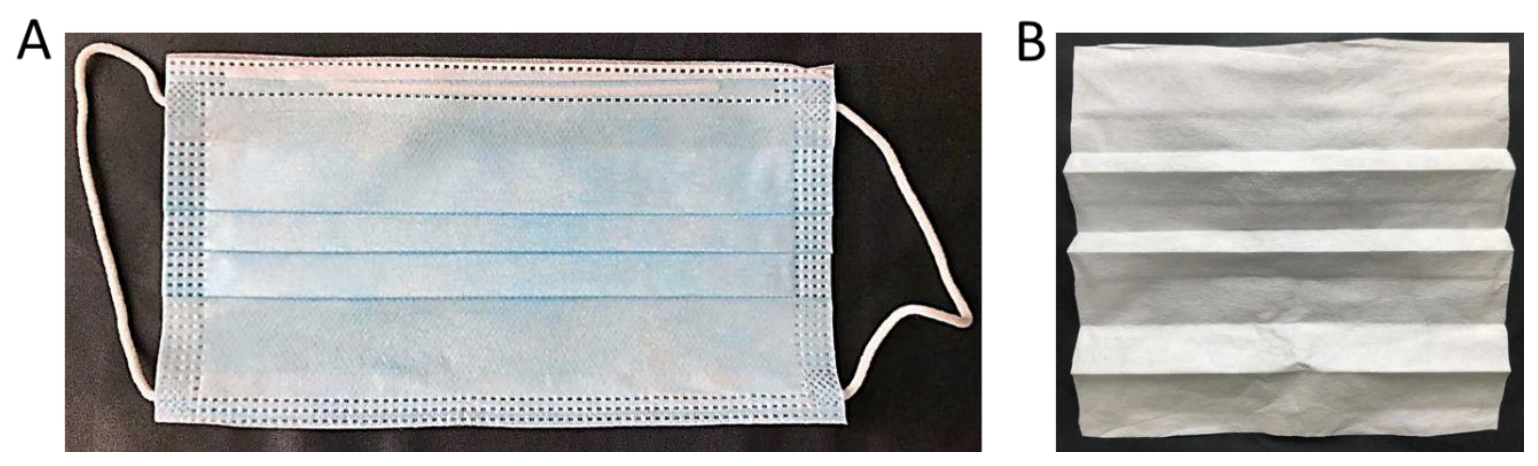

Figure S10. Photo images of a commercial mask. A. the intact mask; B. the filter of the mask. 

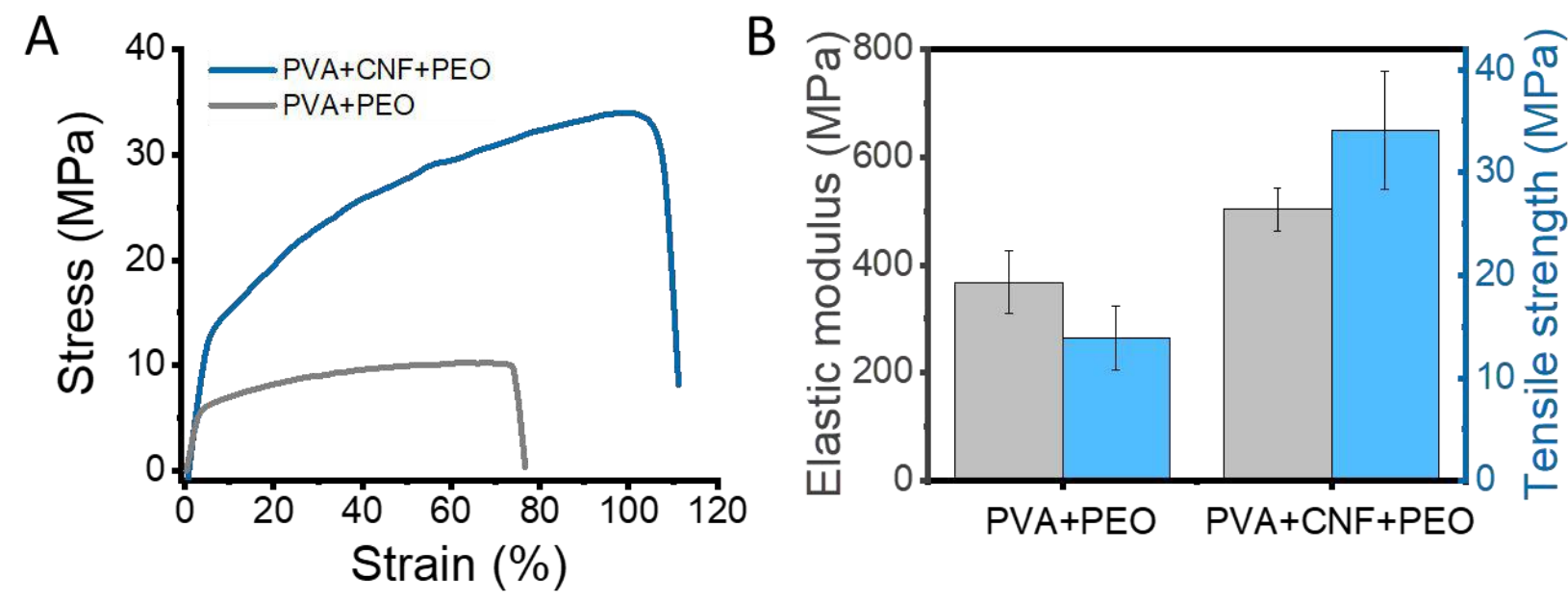

Figure S11. Effects of CNF on the mechanical performances of the as-spun mask materials. A. the stress-strain curve of the mask material with $\mathrm{CNF}$ (PVA+CNF+PEO) and without CNF (PVA+PEO). B. the calculated elastic modulus and tensile strength from the stress strain curve. The data in B represent the average of at least 10 measurements. The data in the panel B can be found in the Table S2. 
Table S2. Mechanical performances of a commercial mask and our mask materials.

\begin{tabular}{lccc}
\hline \multicolumn{1}{c}{ Mask materials } & $\begin{array}{c}\text { Tensile strength } \\
(\mathrm{MPa})\end{array}$ & $\begin{array}{c}\text { Elastic modulus } \\
(\mathrm{MPa})\end{array}$ & $\begin{array}{c}\text { Elongation } \\
(\%)\end{array}$ \\
\hline Commercial mask & $10.7 \pm 1.2$ & $174.1 \pm 14.7$ & $19.0 \pm 3.2$ \\
PVA+PEO & $13.9 \pm 3.1$ & $368.0 \pm 58.9$ & $86.4 \pm 14.3$ \\
PVA+CNF+PEO & $34.1 \pm 5.7$ & $502.7 \pm 39.9$ & $109.8 \pm 9.0$ \\
PVA+CNF+PEO+esterification & $27.2 \pm 3.8$ & $579.1 \pm 18.8$ & $26.6 \pm 3.9$ \\
PVA+CNF+PEO+esterification+TiO 2 & $15.6 \pm 3.8$ & $829.4 \pm 132.6$ & $6.4 \pm 1.9$ \\
PVA+CNF+PEO+esterification+N-TiO & $21.4 \pm 4.6$ & $1853.6 \pm 391.7$ & $5.8 \pm 0.6$ \\
\hline
\end{tabular}



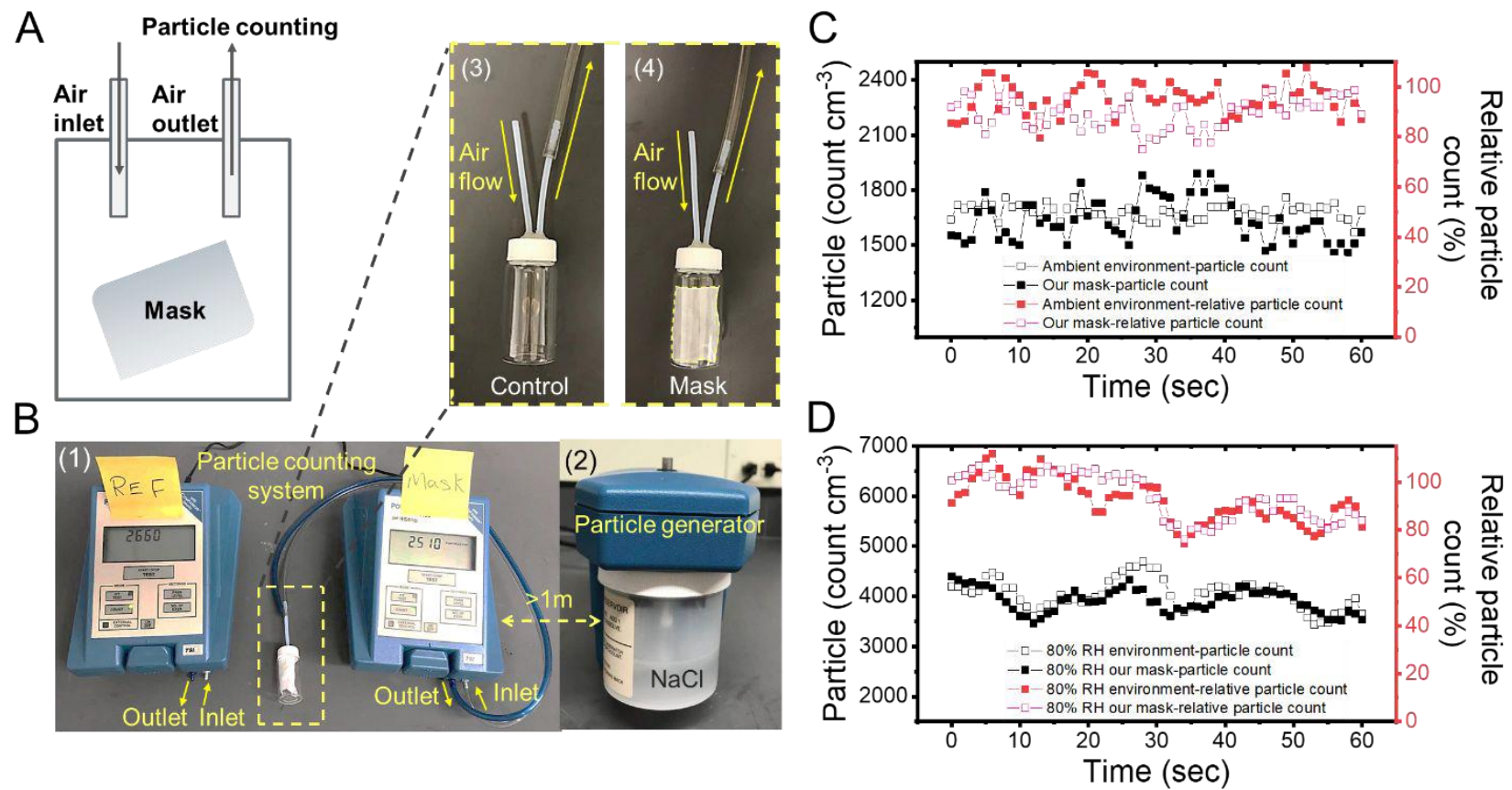

Figure $\mathrm{S} 12$. $\mathrm{TiO}_{2}$ leaking test. A. schematic of $\mathrm{TiO}_{2}$ leaking testing; B. PoartCount system for particle counting. In the panel B, B1 is the PoartCount system with the left one as reference to count the particle in the ambient environment and the right one to count the particle after air flowing through the mask; B2 is the particle generator, which was placed at least one meter away from the PoartCount system; $\mathrm{B} 3$ and $\mathrm{B} 4$ are the home-made devices for $\mathrm{TiO}_{2}$ leaking test, where the mask was sealed in a vial and the air was flowed through the vial. C. particle count and relative particle count (the particle count in the air flow over that in the ambient environment) without humidity control. D. particle count and relative particle count with the humidity control at $80 \%$ RH. 

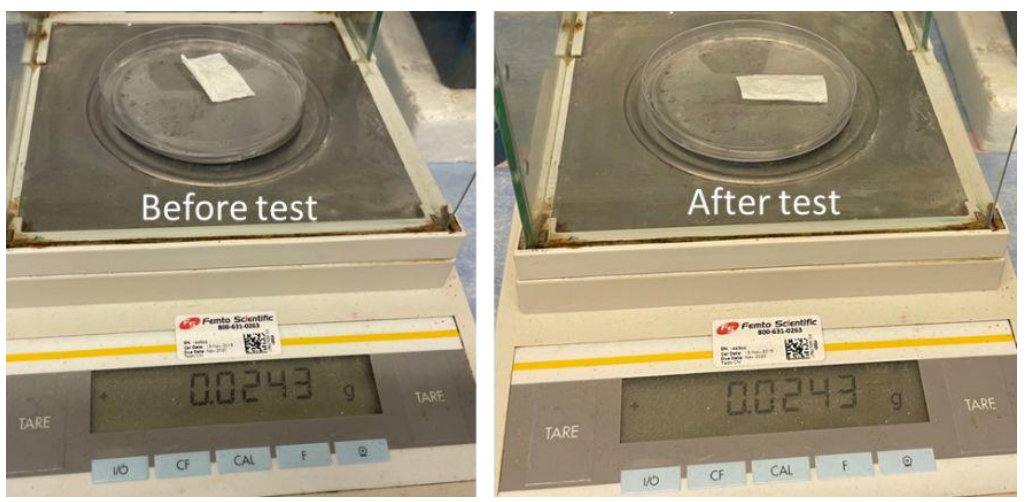

Figure S13. Weight of our mask before and after $\mathrm{TiO}_{2}$ leaking test in an air flow with a high humidity of $80 \% \mathrm{RH}$. 

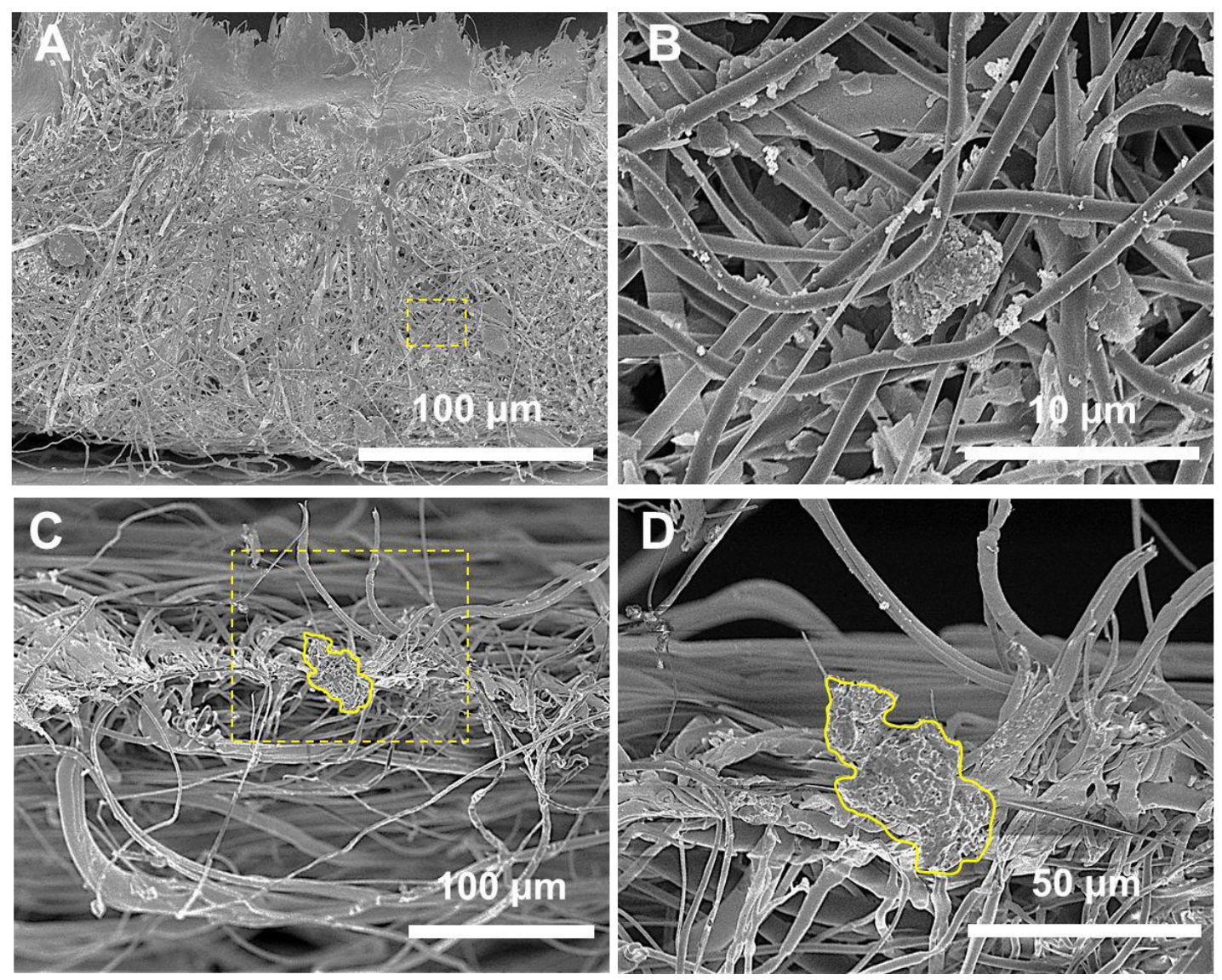

Figure S14. Cross section of a commercial mask (A and B) and our mask (C and D) after filtration efficiency testing after wearing by the author. B and D are the magnified images of the area in the yellow dashed square of A and C, respectively. The edge of the particle on the mask surface in C and D is highlighted by solid yellow line. 
Table S3. Cost estimation of the materials for our mask and a commercial mask.

\begin{tabular}{|c|c|c|c|c|c|c|}
\hline $\begin{array}{c}\text { Mask type } \\
\text { (basis } \\
\text { weight) }\end{array}$ & $\begin{array}{c}\text { Mask } \\
\text { component }\end{array}$ & Price & Qty. & $\begin{array}{c}\text { Cost } \\
(/ \mathrm{Kg} \text { mask })\end{array}$ & $\begin{array}{c}\text { Cost } \\
\left(/ \mathbf{m}^{2} \text { mask }\right)\end{array}$ & Source \\
\hline \multirow{6}{*}{$\begin{array}{l}\text { Our mask } \\
\left(16.8 \mathrm{~g} / \mathrm{m}^{2}\right)\end{array}$} & PVA & $\$ 1.35 / \mathrm{Kg}$ & -- & $\$ 0.6725$ & $\$ 0.0113$ & Alibaba $^{a}$ \\
\hline & $\mathrm{PEO}$ & $\$ 1.60 / \mathrm{Kg}$ & $10 \%$ of PVA & $\$ 0.0797$ & $\$ 0.0013$ & Alibaba $^{b}$ \\
\hline & $\mathrm{CNF}$ & $\$ 2.65 / \mathrm{Kg}$ & $\begin{array}{c}2 \% \text { of } \\
(\mathrm{PVA}+\mathrm{PEO})\end{array}$ & $\$ 0.0290$ & $\$ 0.00049$ & $\begin{array}{c}\text { Delgado- } \\
\text { Aguilar et al } \\
(2015)^{\mathrm{c}}\end{array}$ \\
\hline & $\begin{array}{l}\text { Stearic } \\
\text { acid }\end{array}$ & $\$ 1.0 / \mathrm{Kg}$ & $\begin{array}{c}6.40 \mathrm{~g} / \mathrm{m}^{2} \\
\mathrm{mask}^{\mathrm{i}}\end{array}$ & $\$ 0.3810$ & $\$ 0.0064$ & Alibaba $^{\mathrm{d}}$ \\
\hline & $\mathrm{N}-\mathrm{TiO}_{2}^{\mathrm{h}}$ & $\$ 1.60 / \mathrm{Kg}$ & $\begin{array}{c}1.01 \mathrm{~g} / \mathrm{m}^{2} \\
\mathrm{mask}^{\mathrm{i}}\end{array}$ & $\$ 0.0962$ & $\$ 0.0016$ & Alibaba ${ }^{\mathrm{e}}$ \\
\hline & Total & -- & -- & $\$ 1.2584$ & $\$ 0.0211$ & -- \\
\hline \multirow{2}{*}{$\begin{array}{l}\text { Commerci } \\
\text { al mask } \\
\left(22.4 \mathrm{~g} / \mathrm{m}^{2}\right)\end{array}$} & $\mathrm{PP}$ & $\$ 2.1 / \mathrm{kg}$ & $100 \%$ & $\$ 2.10$ & $\$ 0.0470$ & Alibaba $^{f}$ \\
\hline & $\begin{array}{l}\text { Nonwoven } \\
\text { fibric }\end{array}$ & $\begin{array}{c}\$ 2.9- \\
3.9 / \mathrm{Kg}\end{array}$ & $100 \%$ & $\$ 2.9-\$ 3.9$ & $\begin{array}{l}\$ 0.0650- \\
\$ 0.0874\end{array}$ & Alibaba ${ }^{g}$ \\
\hline
\end{tabular}

a. https://www.alibaba.com/product-detail/Chinese-High-Quality-pva1799-Polyvinyl-Alcohol_62119766490.html

b. https://www.alibaba.com/product-detail/Polyethylene-1000-1500-Chemicals-PolyethyleneGlycol_1600218519303.html?spm=a2700.galleryofferlist.normal_offer.d_title.6cd3767dCcsWTp\&s=p

c. Delgado-Aguilar, M., González, I., Tarrés, Q., Alcalà, M., Pèlach, M. A., and Mutjé, P. Approaching a low-cost production of cellulose nanofibers for papermaking applications. BioRes. 2015, 10(3), 5345-5355.

d. https://www.alibaba.com/product-detail/Stearic-Acid-Stearic-Acid-Type1840_60670056187.html?spm=a2700.galleryofferlist.normal_offer.d_title.21026b8d0Veod2\&s=p

e. https://www.alibaba.com/product-detail/Nitrogen-Doping-TitaniumDioxide_1600210158827.html?spm=a2700.galleryofferlist.normal_offer.d_title.81af665856D5CK

f. https://www.alibaba.com/product-detail/Polypropylene-For-Mask-Non-wovenFabric_62017174471.html?spm=a2700.galleryofferlist.topad_classic.d_title.22d63425xS7oAr

g. https://www.alibaba.com/product-detail/Filter-For-Layers-Mask-MeltblownFilter_1600168497085.html?spm=a2700.galleryofferlist.normal_offer.d_title.42d97799jtK7O4\&s=p

h. The price of industrial $\mathrm{TiO}_{2}$ and $\mathrm{N}-\mathrm{TiO}_{2}$ on Alibaba.com is similar. Therefore, we used only $\mathrm{N}-\mathrm{TiO}_{2}$ for cost estimation.

i. The amounts of esterified stearic acid and the deposited $\mathrm{N}-\mathrm{TiO}_{2}$ were calculated from the weight increment. The results are presented as gram per square meter of mask. 
Table S4. Composition of our mask.

\begin{tabular}{|c|c|c|c|c|c|}
\hline Mask component & PVA & PEO & CNF & $\mathrm{SA}^{\mathrm{a}}$ & $\mathrm{TiO}_{2} / \mathrm{N}^{-\mathrm{TiO}_{2}}$ \\
\hline $\begin{array}{c}\text { Weight percentage } \\
(\%)\end{array}$ & 49.815 & 4.982 & 1.096 & $38.095^{\mathrm{b}}$ & $6.012^{\mathrm{c}}$ \\
\hline
\end{tabular}
a. Stearic acid.
b. Calculated from the weight of the stearic acid reacted with the mask $\left(6.40 \mathrm{~g} / \mathrm{m}^{2}\right.$ mask $)$ divided by mask basis weight $\left(16.8 \mathrm{~g} / \mathrm{m}^{2}\right)$.
c. Calculated from the weight of the $\mathrm{N}-\mathrm{TiO}_{2}$ and $\mathrm{TiO}_{2}$ deposited onto the mask $\left(1.01 \mathrm{~g} / \mathrm{m}^{2}\right.$ mask $)$ divided by mask basis weight $\left(16.8 \mathrm{~g} / \mathrm{m}^{2}\right)$.



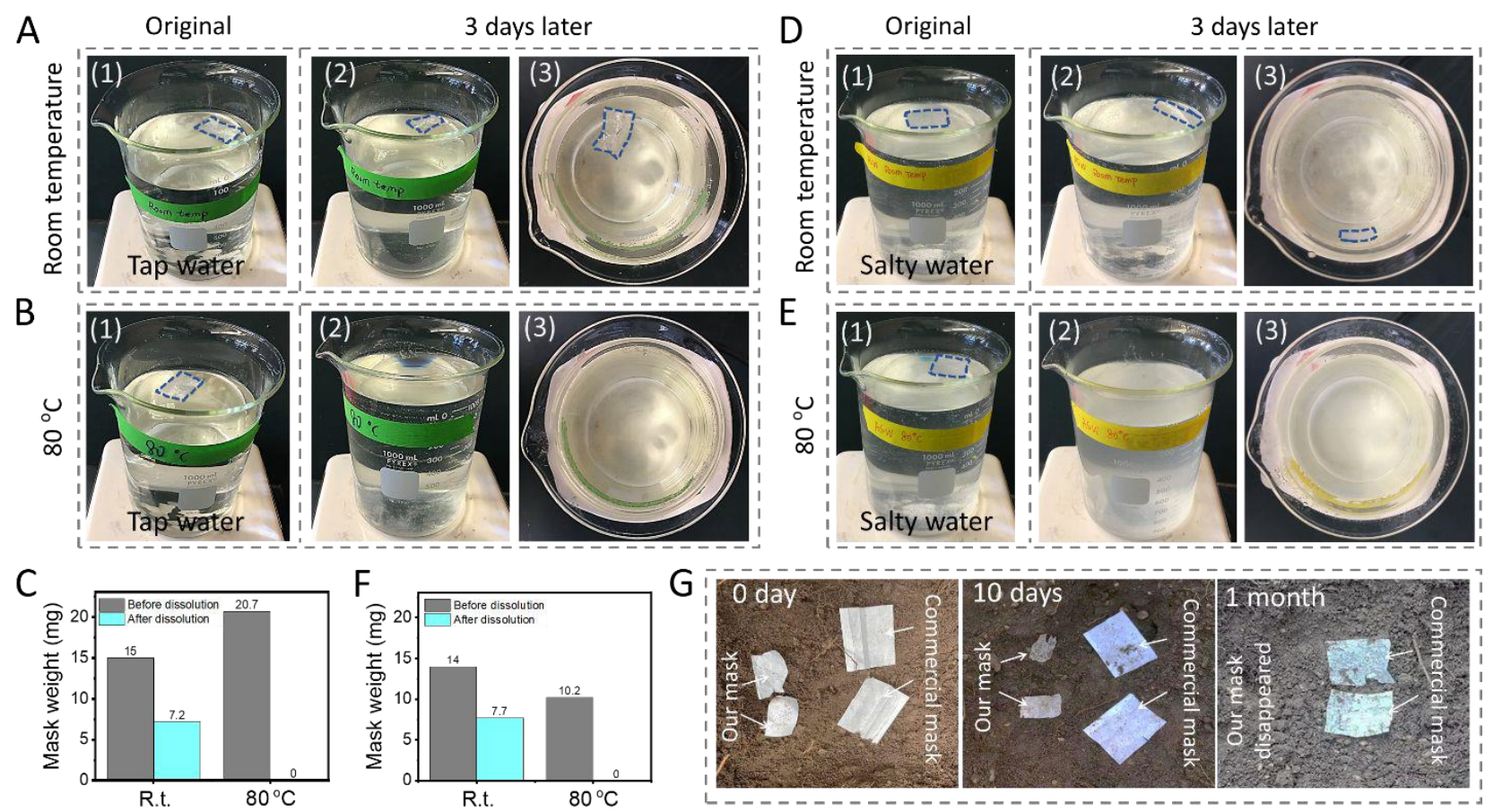

Figure S15. Biodegradability/dissolution of our mask in both water and soil. A and B. dissolution of our mask in tap water at room temperature and $80{ }^{\circ} \mathrm{C}$, respectively; $\mathrm{C}$. the weight change of the mask after putting in tap water for three days; D and E. dissolution of our mask in artificial seawater at room temperature and $80{ }^{\circ} \mathrm{C}$, respectively; F. the weight change of the mask after putting in artificial seawater for three days; G. the change of our mask after burying in soil for a certain period. The dashed lines in the A, B, D, and E indicate the mask sample. 